\title{
SOME LATE SEQUELAE OF HEAD INJURIES DUE TO ROAD ACCIDENTS
}

\author{
Peter H. SChurR, M.A., F.R.C.S. \\ Neurosurgeon to Guy's Hospital and the Bethlem Royal and Maudsley Hospitals, London
}

\begin{abstract}
THE effects of most forms of injury are apparent soon after it has taken place, and, because of the briefness or absence of clouding of consciousness, the patient is immediately aware of them. The late effects of head injury, on the other hand, may not be apparent for months or years, and they may be even more unpleasant and disabling than the initial symptoms. They have far-reaching social effects, and may be responsible for a complete change in the patient's way of life. The patient may even have difficulty in attributing them to the accident.
\end{abstract}

\section{Post-traumatic Intellectual Impairment}

The alterations in the level of consciousness that are passed through by the patient recovering from head injury are illustrated in Table I. Retrograde amnesia is represented in the upper part of the diagram. The duration of retrograde and posttraumatic amnesia has been shown to be a useful, and generally reliable, guide to the severity of the injury. It should be noted that amnesia exists until continuous memory is regained. It cannot, of course, be assessed until the patient has to a large extent recovered. The diagram next represents the completely unconscious state, in which there is no response to any stimuli. The patient recovering from this depth of unconsciousness will initially respond to painful stimuli. As his conscious level becomes lighter he will respond to verbal stimuli, at first without awareness of his environment, and then in states of progressively decreasing disorientation and confusion, until he is apparently fully aware of his surroundings, and able to respond to them in a normal manner. During this stage the patient may return to work. He will have passed well beyond the period of post-traumatic amnesia, and be once again faced with the combat of daily life. Even at this stage, however, he may be suffering from post-traumatic intellectual impairment which only shows in the form of minor defects of memory, judgment, and insight. These may be of little importance to the

A paper read to the Harveian Society of London, November 21, 1962.

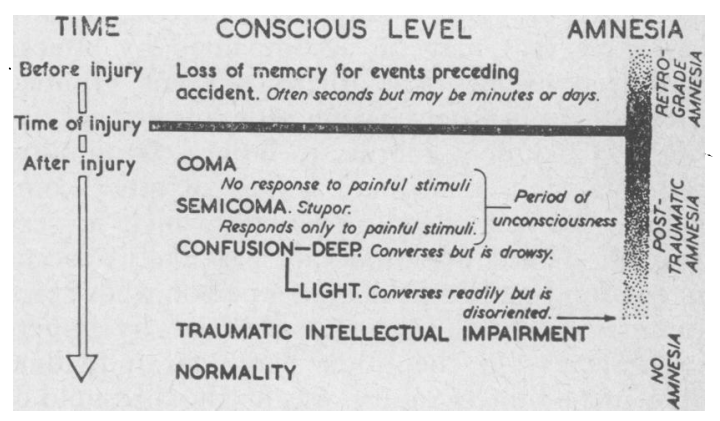

FIG. 1.-Levels of consciousness.

(Reproduced from 'Textbook of Surgery,' edited by Blackburn and Lartie (1958) by kind permission of Blackuell Scientific Publications
Ltd.)

manual worker, but of considerable significance to those in executive or other positions of responsibility. One hopes that the duration of this period may be short, and this is usually the case. In severe head injury it is quite possible for such defects to be permanent.

It has recently been shown (Faust, I962) that brain-damaged persons who sustain their injury before they have completed their education and reached maturity are more likely to need social care and support than those who are injured in later years. If, however, they lack the support of their family during their initial invalidism, or have been physically prevented from earning their living, they may require assistance regardless of age.

\section{Post-Concussion Syndrome}

We should next consider the post-concussion syndrome, or minor contusion syndrome as Sir Charles Symonds has named it (Symonds, 1960). This latter term is better, since a history of concussion is by no means necessary for its occurrence. The syndrome consists of headache, giddiness, and nervous instability of one sort or another, occurring together or separately. The severity and duration of these symptoms bear no relation to the degree of severity of the injury, except that they are more common in cases of prolonged unconsciousness where the post-traumatic amnesia is of long duration. It is quite usual for their onset to be 
delayed, and the patient may leave hospital with none of them. The frequency of this syndrome is in the region of $50 \%$ of cases (see Brenner, Friedman, Merritt and Denny-Brown, I944; and Friedman, Brenner and Denny-Brown, 1945). The headache is usually described as a pressure, or weight, and may be precipitated by stress of any sort, fatigue, or changes of posture. It may last for some weeks or months, and following its disappearance there may still be a persistent liability for it to return. The symptoms of giddiness may be a true vertigo related to damage to the vestibular apparatus, or, more commonly in this context, a dazedness that may be accompanied by attacks of blurred vision. The other symptoms, grouped under the purposely vague title of nervous instability, include a liability to fatigue, irritability, insomnia, depression, and a host of other complaints, the scope and variety of which is very familiar. These symptoms are least likely to occur in the more stable type of young person whose pretraumatic nature was characterized by imperturbability. On the other hand, an individual who, at the time of injury, was on the threshold of depression or other neurosis, may be thrown into overt breakdown as the result of trauma, even to the extent of suicide. In such a case the injury is not a causative factor, and it should not be called a traumatic neurosis, for the trauma was merely the trigger which precipitated it. Nevertheless, it is clear that, in the absence of such a precipitating factor, the patient might well have carried on (Symonds, I960). It is a short step to the consideration of the so-called compensation neuroses, and there is no doubt that litigation can both prolong symptoms of a neurotic nature, or give rise to those of hysterical origin. The fact of their occurrence, however, constitutes a disability, and is dependent largely on the personality of the individual before the accident. Except in the case of frank malingering, these symptoms have perforce to be regarded as a result of the head injury, and it is worth remembering that they may persist after the litigation has been settled.

\section{Post-traumatic Epilepsy}

One of the most serious sequelæ of head injury is that of epilepsy, which, from its social and economic consequences, can cripple a patient more than a hemiplegia. On account of its relative unpredictability it is a hazard which is extremely difficult to assess in terms of any monetary compensation for injury, and in arriving at a prediction one has to depend on information derived from statistics of large numbers of injuries of different types. Of the recent analyses of large series of cases, those of Walker and Jablon (1959) on war injuries, and Jennett ( 1962 ) on civilian injuries, are significant. In the uncomplicated head injury,ån which there has been no depressed fracture, cersbral contusion, or laceration, etc., the incidencesf epilepsy is only $\mathrm{I}-\mathrm{I} .5 \%$, even when the posttraumatic amnesia is 24 hours or more. Howev $\overrightarrow{\mathrm{fr}}$, when a depressed fracture is present together with prolonged post-traumatic amnesia, the incidenceff late epilepsy is as much as $57 \%$. The occurrenge of fits in the early stages after head injury liss formerly been regarded as of little significance, but this may be because information was largely based on war injuries (i.e., high velocity missile wounds). In Jennett's civilian series he found the incidenete of late epilepsy was $28.5 \%$ when an early fit higd taken place, and only $7.5 \%$ in all other patiens⿱乛龰s. Penetration and tearing of the dura mater 9 s associated with a very high risk of late epilepsy $\rightarrow$ ags much as $80 \%$ when combined with prolonged amnesia or an early fit. After acute intracranial hæmatomata and chronic subdural hæmatomata the incidence was about $28.5 \%$ (Jennett, 196\%.

Although the risk of epilepsy can be estimated in this way, the longer a patient is free from epilepsy, the less likely it is to occur, and Walk (1959) has stated that if a patient with a close्g head injury has had no attack in two years, or person with an open head injury none in ten yegra, he has no greater chance of epilepsy than $t$ the general population, though there are surgeons who would regard this as over optimat. $\mathrm{He}$ also found that if seizures did not average morfe than one in two months during the first five yeang, with or without medication, the chances weppe better than $66 \%$ that they would stop altogether. The occurrence of frequent attacks in the eary years does not necessarily mean that they will become uncontrollable later, but it is interesti that although major attacks tend to decrease in frequency during the first three years, mingr seizures may not behave in this way. More thay half the cases of post-traumatic epilepsy are like to occur for the first time within a year of injuris, but a quarter do not appear until after the $4^{\text {th }}$ year. Epilepsy is more likely to be delayed when the injury is severe. One should make a qualification in the case of children, who are much more liabte than adults to early seizures following head injur $\overline{\overline{\mathrm{b}}}$ and in whom early attacks are very much less significant from the point of view of late epileps架

\section{Other Late Sequelæ of Head Injury}

There are other late sequelæ which occur with relative frequency and are to some extent pr® ventable. Among these is the late occurrence of meningitis, frontal aerocele and abscess, associate with fractures involving the frontal, ethmoid and sphenoidal air sinuses. The fact of cessation. 
of cerebrospinal rhinorrhœa after a head injury is no criterion of safety. The appearance of meningitis may be delayed by years, so that its origin may be unrecognized, with the consequence that its treatment is symptomatic and not causative; the patient is then liable to further and possibly fatal attacks of meningitis. It is difficult to generalize, but at least it is wise to consider performing a dural repair in any patient who has suffered cerebrospinal rhinorrhœa, when the fracture line is more than a millimetre in width in the X-ray, or when there is a visible displacement of bone. The late occurrence of abscesses elsewhere in the brain is more common in war injuries, and is likely to be associated with the presence of a foreign body. This unpleasant and dangerous sequel can often be prevented by careful surgery in the early stages of treatment.

One need do no more than mention chronic subdural hæmatomas and hygromas, and the still questionable late occurrence of meningiomas following injury.

It is to be hoped that the greater provision of adequate facilities for treatment may reduce the frequency of these unpleasant complications of head injury, but more than this is required for the proper rehabilitation of patients. Unless it is generally realized that people suffering from those symptoms of headache, giddiness, and alteration of personality, are not to be classed as malingerers, or labelled 'functional' and disposed of as rapidly as possible, there will continue to be a wastage of manpower and a persistence of suffering in a large number of individuals. Their treatment is by no means simple, and it is by no means easy to find the right person to carry it out. Above all, the patient needs understanding, and the clinician needs confidence. The relief of epilepsy has been greatly helped by recent advances in materia medica, but, although some help may be derived from surgery at a time remote from the injury, there can be no doubt that efficient treatment in the initial stages provides a more valuable contribution.

The importance which must be attached to the prevention of head injury cannot be overemphasized. The sequelæ mentioned owe their origin to factors arising before and at the time of the accident. After the accident has occurred, with the exception of those of infective origin, they can only be mitigated, they cannot be prevented.

\section{REFERENCES}

Brenner, C., Friedman, A. P., Merritt, H. H., and Denny-Brown, D. (1944): Post-traumatic Headache, f. Neurosurg., I, 379.

FAust, CL. (1962): Der Hirntraumaticker in der Gesellschaft, Freiburger med. Forsch., I, 92.

Friedman, A. P., Brenner, C., and Denny-Brown, D. (1945): Post-traumatic Vertigo and Dizziness, F. Neurosurg., 2,36 .

JennetT, W. B. (1962): 'Epilepsy After Blunt Head Injuries'. London: Heinemann.

SymondS, C. P. (1 960): Concussion and Contusion of the Brain and Their Sequelæ. In 'Injuries of the Brain and Spinal Cord'. Ed. S. Brock, 4th edition, ch. 4, p. 69. London: Cassell.

Walker, A. E. (I 959): ' Clinical Neurosurgery', 6, 69. Baltimore: Williams and Wilkins.

- and Jablon, S. (1959): A Follow-up of Head-injured Men of World War II, F. Neurosurg., 16, 600. 